\title{
Monozygotic twins with infantile neuroaxonal dystrophy: A case report and literature review
}

\author{
HAIFENG LI $^{1}$, YAN ZOU ${ }^{2}$, XINHUA BAO ${ }^{3}$, HUI WANG ${ }^{1}$, JIANGPING WANG ${ }^{1}$, \\ HUIYING JIN ${ }^{1}$, YUPING $\mathrm{CHE}^{1}$ and XIAOYAN TANG ${ }^{4}$

\begin{abstract}
${ }^{1}$ Rehabilitation Department, The Children's Hospital, Zhejiang University School of Medicine; ${ }^{2}$ Nutrition and Food Safety Department, Zhejiang Provincial Center for Disease Control and Prevention, Hangzhou, Zhejiang 310051;

${ }^{3}$ Pediatric Department, Peking University First Hospital; ${ }^{4}$ Clinical Laboratory of Zhongke, Beijing 100034, P.R. China
\end{abstract}

Received August 26, 2015; Accepted August 11, 2016

DOI: $10.3892 / \mathrm{etm} .2016 .3761$

\begin{abstract}
Infantile neuroaxonal dystrophy (INAD) is a rare neurodegenerative disease with early onset. PLA2G6 gene mutations have been identified in the majority individuals with INAD. In future, molecular diagnosis of INAD will replace the invasive biopsies used previously. In the present report, monozygotic male twins with INAD were referred The Children's Hospital (Zhejiang University School of Medicine, Zhejiang, China) at fifteen months old for delayed development. The older brother was found to have developmental stagnation when he was 6 months old. The patient could not stand securely without support, and had poor eye tracking and listening ability. Magnetic resonance imaging (MRI) of the patient's brain revealed cerebellar atrophy and electromyography identified signs of peripheral neuropathy. The younger brother displayed similar clinical features and findings. Two different phospholipase A2 group VI (PLA2G6; 22q13.1) gene mutations were detected in the twins by DNA sequencing. The results of the present study indicate that neurogenetic disease should be considered when child patients present with idiopathic developmental stagnation, particularly when similar cases have appeared in the same family. In addition, INAD should be considered as a possible diagnosis when the patient has developmental delay of the central and peripheral nerves. In the future, molecular genetic testing will be the primary method of INAD diagnosis, enabling better prevention of this genetic disease.
\end{abstract}

Correspondence to: Ms. Yan Zou, Nutrition and Food Safety Department, Zhejiang Provincial Center for Disease Control and Prevention, 3399 Binsheng Road, Hangzhou, Zhejiang 310051, P.R. China

E-mail: zouyan0573@163.com

Key words: infantile neuroaxonal dystrophy, phospholipase A2 group VI, magnetic resonance imaging

\section{Introduction}

Infantile neuroaxonal dystrophy (INAD) is a rare autosomal recessive neurodegenerative disorder, characterized by an early symptomatic onset with rapid progression of psychomotor regression and hypotonia, evolving into spasticity. This results in total neurological degeneration and mortality by the age of 10. There is no effective treatment for INAD at present and since it is a rare disorder, involving axons in the central and peripheral nervous system, there is little literature on the disease. Therefore, it is important to provide accurate genetic counseling for families with INAD.

INAD sufferers exhibit spheroid bodies in the central nervous system and pathological swelling of axons (1). In addition, T2-weighted magnetic resonance imaging (MRI) of patients with INAD typically reveals cerebellar atrophy, however, MRI is not used as the primary method of INAD diagnosis $(2,3)$. Prior to molecular testing for phospholipase A2 group VI (PLA2G6; 22q13.1) mutations, which have been identified in the majority of INAD sufferers, an INAD diagnosis could be only be confirmed through electron microscopy identification of axon dystrophy in a tissue biopsy of conjunctiva, skin, muscle or sural nerves (4). Molecular diagnosis of INAD eliminates the need for invasive biopsies, enables the detection of carriers of INAD-associated mutations and allows for prenatal diagnosis. The present study reports the case twins with INAD caused by PLA2G6 mutations inherited from the mother and father, which highlights the importance of genetic testing in the diagnosis and prevention of INAD.

\section{Case report}

The current report presents monozygotic male twins with INAD referred to The Children's Hospital (Zhejiang University School of Medicine, Zhejiang, China) in December 2013 at 15 months old with delayed development. Written informed consent for participation in the current study was obtained from the guardians. The parents were a non-consanguineous healthy Chinese couple, with no significant family history and an older child (female, 8 years old) that was healthy. The twins were born at term, following an uneventful pregnancy, by cesarean section. The patients were asymptomatic at birth 
and achieved normal developmental milestones, including looking up, standing up and sitting independently, until they were 6 months old. Disease onset occurred when the patients were between 7 and 15 months old, where they could not stand securely without support, and exhibited poor eye tracking and listening ability. Clinical examination revealed slow reactions, a limb muscle strength of grade IV and a muscle tension level of 1. Electromyography identified signs of peripheral neuropathy. Electroencephalogram showed slow background activity. MRI imaging of the brain revealed cerebellar atrophy (Fig. 1).

Polymerase chain reaction (PCR) amplification was performed to screen for PLA2G6 mutation. The Whole Blood Genome DNA Isolation kit (cat. no. 2013-1400049; Beijing ComWin Biotech Co., Ltd., Beijing, China) was used to obtain DNA from the patients, according to the manufacturer's instructions. PCR was performed using the PCR Amplification Kit (cat. no. R011) and Ex Taq DNA polymerase (both Takara Biotechnology Co., Ltd., Dalian, China). The PCR reaction included 10X Ex Taq buffer (3 $\mu 1), 2.5 \mathrm{mM}$ dNTPs $(2.4 \mu \mathrm{l})$, Primer F $(10 \mu \mathrm{M} ; 0.6 \mu \mathrm{l})$, Primer R $(10 \mu \mathrm{M} ; 0.6 \mu \mathrm{l})$, template DNA $(1 \mu \mathrm{l})$, Ex Taq $(5 \mathrm{U} / \mu \mathrm{l} ; 0.15 \mu \mathrm{l})$, and water $(22.25 \mu \mathrm{l})$. The thermal cycling conditions were as follows: $94^{\circ} \mathrm{C}$ for $3 \mathrm{~min}$, $94^{\circ} \mathrm{C}$ for $30 \mathrm{sec}, 55^{\circ} \mathrm{C}$ for $30 \mathrm{~s}, 36$ cycles of $55^{\circ} \mathrm{C}$ for $1 \mathrm{~min}$, and totally 36 cycles, and $72^{\circ} \mathrm{C}$ for $5 \mathrm{~min}$. DNA sequencing was performed using the ABI PRISM BigDye Terminator v3.1 Cycle Sequencing kit (cat. no. 4337455; Applied Biosystems; Thermo Fisher Scientific, Inc., Waltham, MA, USA), according to the manufacturer's instructions, and an Applied Biosystems 3100 Genetic Analyzer (Thermo Fisher Scientific, Inc.) to detect the following mutations: Exon 2 A1 (A/G), exon 2 G87 (G/A) and exon $13 \mathrm{C} 1771(\mathrm{C} / \mathrm{T})$. Interestingly, two different PLA2G6 mutations were detected in the twins, exon $2 \mathrm{~A} 1 \mathrm{~A} / \mathrm{G}$ and exon $13 \mathrm{C} 1771 \mathrm{C} / \mathrm{T}$ (Fig. 2A and B). The Met1Val of A1 A/G was from the father (Fig. 2C) and the Arg591Trp of C1771 $\mathrm{C} / \mathrm{T}$ was from mother (Fig. 2D).

\section{Discussion}

INAD is a severe early onset neurodegenerative disease. Clinical and neurophysiological findings alone may be insufficient for early diagnosis of INAD. MRI examination (T2-weighted) of patients with INAD typically reveals marked cerebellar atrophy and a signal hyperintensity of the cerebellar cortex. Nardocci et al (1) proposed clinical diagnostic criteria for INAD. However, developments in molecular diagnosis have showed that the majority of INAD cases are associated with mutations in the PLA2G6 gene (4). PLA2G6, which encodes the $\mathrm{Ca}^{2+}$-independent phospholipase A2 $\beta$, iPLA2 $\beta$, has been identified as a causative gene of INAD (5). The enzyme iPLA2 $\beta$ serves a key role in membrane composition, via hydrolysis of peroxidized fatty acid, and in signal transduction. The determination that PLA2G6 mutations are the cause of INAD has revolutionized the ability to diagnosis this disorder (6). Khateeb et al (7) demonstrated the role of phospholipase mutation in neurodegenerative disorders. Malik et al (8) indicated that loss of iPLA2 $\beta$ function triggers age-dependent impairment of protein degradation signaling pathways and homeostasis of the axonal membranes, resulting in age-related neurological impairment. Polster et al (9) suggested that PLA2G6 serves a role in neuronal proliferation

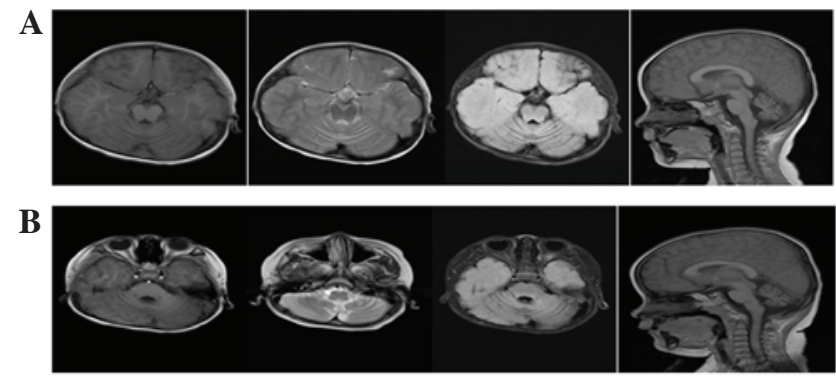

Figure 1. Sagittal T2-weighted MRI showed vermis and hemisphere atrophy of the cerebellums of (A) the older twin and (B) the younger twin.
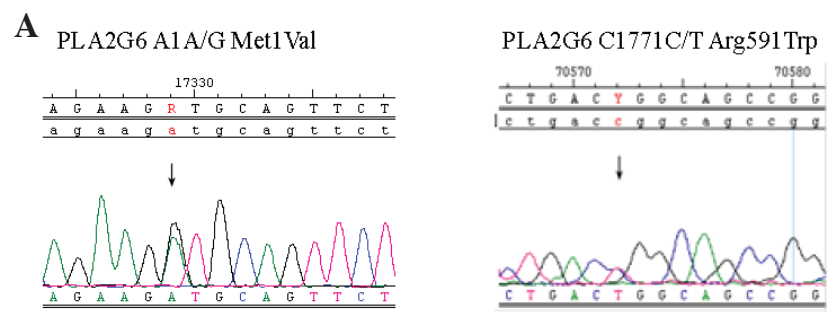

B

PLA2G6 A1A/G Met1Val

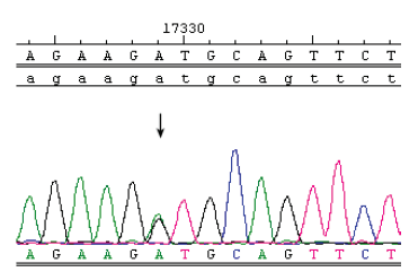

PLA2G6 C1771C/T Arg591Trp

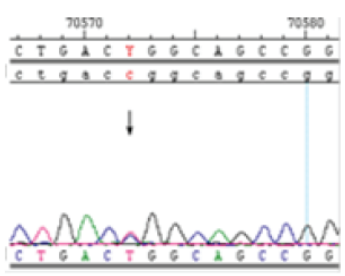

C

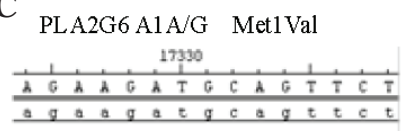

$\downarrow$

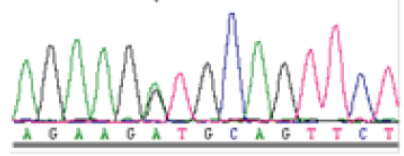

D

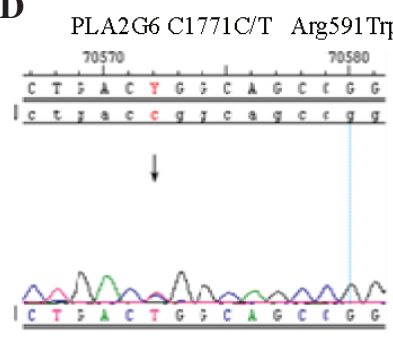

Figure 2. DNA sequencing analysis of the PLA2G6 mutations in the (A) older twin, (B) younger twin, (C) father of the twins and (D) mother of the twins.

in the developing brain, neurons, cortical plate and hindbrain. PLA2G6 expression is widespread in neuronal tissues, however, the expression pattern changes dynamically over time, which suggests that INAD pathogenesis begins prenatally. Mutations in the gene encoding iPLA2 $\beta$ are found in $\sim 85 \%$ of patients with INAD and Strokin et al (10) suggests that altered $\mathrm{Ca}^{2+}$ signaling is the key mechanism in the development of INAD. In addition, Biancheri et al (11) reported that a 2-year-old boy presenting with hypotonia and psychomotor regression, whose MRI showed cerebellar atrophy with normal cerebellar cortex signal intensity, had a homozygous 5' splice site PLA2G6 mutation (12). This indicates that the absence of cerebellar cortex signal hyperintensity does not rule out an INAD diagnosis (13). 
Previous studies containing the phrase 'INAD and PLA2G6' were identified in PubMed (http://www.ncbi.nlm.nih.gov/ pubmed), resulting in 61 papers from 2006 to 2015. Since 2006, just 11 genetic studies of patients with INAD have been published (2,6,12-17). In China, only 2 studies reported PLA2G6-associated neurodegeneration. The first study discussed 10 patients with INAD, who had been diagnosed through neuropathology, that were analyzed for PLA2G6 mutations (17). The second was a follow-up study of 25 Chinese children with PLA2G6-associated neurodegeneration that found 27 different mutations, of which 13 were novel (18).

In conclusion, the results of present study highlight that in children who present with early, rapid cognitive and motor regression, and axial hypotonia, INAD is an important differential diagnosis. In this regard, neurogenetic disease should be considered in children with developmental stagnation of an unknown cause, particularly when similar cases have appeared within their family. Furthermore, INAD should be considered when children have delayed central and peripheral nerve development. In future, genetic testing will be the primary method used for INAD diagnosis. In addition, this testing could be used for carrier detection and prenatal diagnosis in affected families, in order to facilitate a more precise assessment of the recurrence risks, to guide prenatal care and to prevent genetic diseases.

\section{Acknowledgements}

The present study was supported by Zhejiang Province Science and Technology Fund (grant no. 2015C33178).

\section{References}

1. Nardocci N, Zorzi G, Farina L, Binelli S, Scaioli W, Ciano C, Verga L, Angelini L, Savoiardo M and Bugiani O: Infantile neuroaxonal dystrophy: Clinical spectrum and diagnostic criteria. Neurology 52: 1472-1478, 1999.

2. Kurian MA, Morgan NV, MacPherson L, Foster K, Peake D, Gupta R, Philip SG, Hendriksz C, Morton JE, Kingston HM, et al: Phenotypic spectrum of neurodegeneration associated with mutations in the PLA2G6 gene (PLAN). Neurology 70: 1623-1629, 2008.

3. Farina L, Nardocci N, Bruzzone MG, D'Incerti L, Zorzi G, Verga L, Morbin M and Savoiardo M: Infantile neuroaxonal dystrophy: Neuroradiological studies in 11 patients. Neuroradiology 41: 376-380, 1999.

4. Gregory A, Westaway SK, Holm IE, Kotzbauer PT, Hogarth P, Sonek S, Coryell JC, Nguyen TM, Nardocci N, Zorzi G, et al: Neurodegeneration associated with genetic defects in phospholipase A(2). Neurology 71: 1402-1409, 2008.
5. Wada H, Kojo S and Seino K: Mouse models of human INAD by Pla2g6 deficiency. Histol Histopathol 28: 965-969, 2013.

6. Morgan NV, Westaway SK, Morton JE, Gregory A, Gissen P, Sonek S, Cangul H, Coryell J, Canham N, Nardocci N, et al: PLA2G6, encoding a phospholipase A2, is mutated in neurodegenerative disorders with high brain iron. Nat Genet 38: 752-754, 2006.

7. Khateeb S, Flusser H, Ofir R, Shelef I, Narkis G, Vardi G, Shorer Z, Levy R, Galil A, Elbedour K and Birk OS: PLA2G6 mutation underlies infantile neuroaxonal dystrophy. Am J Hum Genet 79: 942-948, 2006.

8. Malik I, Turk J, Mancuso DJ, Montier L, Wohltmann M, Wozniak DF, Schmidt RE, Gross RW and Kotzbauer PT: Disrupted membrane homeostasis and accumulation of ubiquitinated proteins in a mouse model of infantile neuroaxonal dystrophy caused by PLA2G6 mutations. Am J Pathol 172: 406-416, 2008.

9. Polster B, Crosier M, Lindsay S and Hayflick S: Expression of PLA2G6 in human fetal development: Implications for infantile neuroaxonal dystrophy. Brain Res Bull 83: 374-379, 2010.

10. Strokin M, Seburn KL, Cox GA, Martens KA and Reiser G: Severe disturbance in the $\mathrm{Ca} 2+$ signaling in astrocytes from mouse models of human infantile neuroaxonal dystrophy with mutated Pla2g6. Hum Mol Genet 21: 2807-2814, 2012.

11. Biancheri R, Rossi A, Alpigiani G, Filocamo M, Gandolfo C, Lorini R and Minetti C: Cerebellar atrophy without cerebellar cortex hyperintensity in infantile neuroaxonal dystrophy (INAD) due to PLA2G6 mutation. Eur J Paediatr Neurol 11: 175-177, 2007.

12. Frattini D, Nardocci N, Pascarella R, Panteghini C, Garavaglia B and Fusco C: Downbeat nystagmus as the presenting symptom of infantile neuroaxonal dystrophy: A case report. Brain Dev 37: 270-272, 2015.

13. Solomons J, Ridgway O, Hardy C, Kurian MA, Jayawant S, Hughes S, Pretorius P and Németh AH: Infantile neuroaxonal dystrophy caused by uniparental disomy. Dev Med Child Neurol 56: 386-389, 2014.

14. Riku Y, Ikeuchi T, Yoshino H, Mimuro M, Mano K, Goto Y, Hattori N, Sobue G and Yoshida M: Extensive aggregation of $\alpha$-synuclein and tau in juvenile-onset neuroaxonal dystrophy: An autopsied individual with a novel mutation in the PLA2G6 gene-splicing site. Acta Neuropathol Commun 1: 12, 2013.

15. Tonelli A, Romaniello R, Grasso R, Cavallini A, Righini A, Bresolin N, Borgatti R and Bassi MT: Novel splice-site mutations and a large intragenic deletion in PLA2G6 associated with a severe and rapidly progressive form of infantile neuroaxonal dystrophy. Clin Genet 78: 432-440, 2010.

16. Carrilho I, Santos M, Guimarães A, Teixeira J, Chorão R, Martins M, Dias C, Gregory A, Westaway S, Nguyen T, et al: Infantile neuroaxonal dystrophy: What's most important for the diagnosis? Eur J Paediatr Neurol 12: 491-500, 2008.

17. Wu Y, Jiang Y, Gao Z, Wang J, Yuan Y, Xiong H, Chang X, Bao X, Zhang Y, Xiao J and Wu X: Clinical study and PLA2G6 mutation screening analysis in Chinese patients with infantile neuroaxonal dystrophy. Eur J Neurol 16: 240-245, 2009.

18. Zhang P, Gao Z, Jiang Y, Wang J, Zhang F, Wang S, Yang Y, Xiong $\mathrm{H}$, Zhang Y, Bao X, et al: Follow-up study of 25 Chinese children with PLA2G6-associated neurodegeneration. Eur J Neurol 20: 322-330, 2013. 